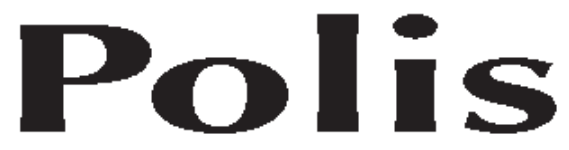

\title{
Un análisis alternativo de la actual crisis económica global y sus vías de superación
}

Luis Razeto M.*

Resumen: Se examina en este artículo la actual crisis económica global, desde una óptica alternativa y distante de las visiones que predominan entre los analistas económicos convencionales, así como de aquellas interpretaciones que postulan algunos pensadores "alternativos". El autor -basándose en la que denomina "teoría económica comprensiva"sostiene que en lo esencial, esta crisis hunde sus raíces en una distorsión del sistema monetario imperante a nivel global, que está significando que el dinero ha perdido su capacidad de cumplir sus funciones esenciales. Argumenta en seguida que las políticas keynesianas por las que se busca actualmente enfrentar esta crisis, lejos de contribuir a superarla la acentuarán y prolongarán, hasta que se establezca un nuevo sistema monetario, en el contexto de una diversa estructuración del mercado, que no podrá ocurrir hasta que se cumplan grandes reformas culturales, institucionales, jurídicas y políticas.

Palabras clave: Crisis financiera, crisis económica global, Keynesianismo, mercado, superación de la crisis, "otra economía", nuevo orden económico mundial, crisis energética, depresión económica.

\section{An alternative analysis of the current global economic crisis and the ways to overcome it}

Abstract: It is examined in this article the current global economic crisis, from an alternative point of view, and distant from the visions that dominate among conventional economic analysts, as well as of those interpretations that offer some "alternative" thinkers. The author -basing himself on what he calls "comprehensive economic theory"- argues that essentially this crisis is rooted in a distortion of the prevailing monetary system at global level, which is signifying that money has lost its capacity of complying its essential functions. He argues then that the Keynesian politics by which it is sought at present to face this crisis, far from contributing to surpass it will accentuate it and prolong it, until a new monetary system is established, in the context of structuring the market in a different way, which will not occur until large political, legal, institutional, and cultural reforms are fulfilled.

Key words: Financial crisis, global economic crisis, Keynesianism, market, beating of the crisis, "another economy”, new world economic order, energy crisis, economic depression.

Recibido: 05.11.08

Aceptado: 25.11 .08

$$
* * *
$$

\footnotetext{
*Universidad Bolivariana, Santiago, Chile. Email: 1razeto@ubolivariana.cl
} 


\section{Crisis, mercado y "otra economía"}

A menudo quienes aspiran o activamente se esfuerzan en construir "otra economía" más justa, solidaria, no capitalista-, tienden a observar la economía dominante como experimentando una crisis profunda, y esperan que de algún modo sobrevenga un colapso, una demolición, una paralización del mercado, por efecto de su propio peso, de sus contradicciones internas, de sus crisis. Se piensa que cuando ocurra el colapso del mercado será el momento de la "otra economía", que mientras tanto se estaría construyendo sólo en pequeña escala, como prefiguración o antecedente de lo que será, en gran escala, después de la catástrofe. En presencia de lo que parece ser hoy el comienzo de una "gran crisis" económica, muchos anuncian que está a punto de verificarse el fin del capitalismo y, por tanto, que se abre la oportunidad para que la "otra economía" se despliegue como la gran solución anhelada. Sobre las causas y profundidad de esta crisis económica actual, y sobre sus posibles soluciones y vías de salida, ofrecemos a continuación una serie de análisis y reflexiones -basadas en nuestra "teoría económica comprensiva"- que esperamos sirva a una mejor intelección de la cuestión enunciada.

Muchos se imaginan el colapso del "sistema" como un edificio que se derrumba entero; y en consecuencia, la construcción de la "otra economía", como una edificación completamente nueva, que tal vez pueda aprovechar algunos trozos del edificio derrumbado, que pudieran ser reciclados e integrados al nuevo orden económico.

Más allá de que palabras como "derrumbe" o "colapso", aplicadas a la economía son solamente metáforas, considero necesario precisar algunos conceptos, para adquirir una perspectiva más realista respecto del futuro y en relación a las condiciones que pueden esperarse para acelerar la construcción de "otra economía". Esto es necesario particularmente hoy que el mundo está inmerso en una gran crisis financiera que hace pensar a muchos que el momento del colapso se aproxima o estaría ya por acaecer.

Primera precisión. El mercado no se detiene, no deja de funcionar, no se derrumba (a menos que sobrevenga una catástrofe que destruya la vida social, por causas exógenas al mercado como tal), por más que experimente crisis financieras y económicas de considerable envergadura. Porque el mercado es la interacción y la coordinación de las decisiones de producción, distribución y consumo que efectúan permanentemente los seres humanos y sus organizaciones. Desde que existen, y mientras existan seres humanos y organizaciones, ha habido y habrá intercambios entre ellos, y el mercado seguirá funcionando.

Segunda precisión. El mercado en su evolución histórica ha experimentado y experimentará transformaciones que pueden ser muy profundas, estructurales (como se acostumbra decir). Las transformaciones más importantes y profundas, las experimenta el 
mercado cuando ocurren en la sociedad fenómenos que impactan profundamente la vida colectiva, tales como guerras, devastaciones naturales, descubrimientos o conquistas de nuevos territorios, innovaciones tecnológicas de alto impacto, incorporación o agotamiento de importantes fuentes de energía, revoluciones sociales, instauración de un nuevo sistema político, etc. En tal sentido, es esencial comprender que el mercado se encuentra determinado, que no existe en sí mismo, que no funciona exclusivamente en base a sus propias dinámicas internas. El mercado es siempre un "mercado determinado". En tal sentido, no puede descartarse que el mercado llegue a colapsar, hundiendo a las sociedades en un abismo de decadencia catastrófica; pero ello no puede ocurrir por causas inherentes al funcionamiento del mercado mismo, sino por impactos exógenos. Hoy, por ejemplo, pudiera ocurrir un colapso económico si las economías fueran afectadas por un drástico cambio climático, o por un acelerado agotamiento de las disponibilidades de petróleo y otras fuentes de energía.

Tercera precisión. No obstante lo anterior, debe reconocerse que el mercado es capaz de resistir impactos exógenos muy fuertes, frente a los cuales reacciona conforme a sus propias dinámicas internas. Una guerra mundial o una guerra civil pueden alterar drásticamente la conformación del mercado y la participación en él de los sujetos, pero el mercado sigue funcionando en esos contextos modificados. El mercado sigue funcionando y reacciona con sus propias racionalidades cuando se producen catástrofes naturales, cambios tecnológicos, disminución de los recursos y fuentes de energía, etc.

Cuarta precisión. Las dinámicas internas del mercado, en el sentido de sus ciclos, sus crisis y sus fases de expansión, los fenómenos de inflación y crecimiento, estancamiento o depresión, sus cambios a nivel de los sistemas e instituciones monetarias y financieras, sus procesos de concentración y distribución de la riqueza, son dinámicas que pueden impactar muy hondamente el funcionamiento de la producción, la distribución de la riqueza, los niveles de consumo y los ritmos de crecimiento. Pero por sí mismas, tales dinámicas no conducen a una interrupción del funcionamiento del mercado, no lo detienen, no lo hacen colapsar en el sentido de un edificio que se cae y del que sólo quedan escombros que recoger. Los cambios y las crisis más hondas que puede experimentar el mercado como efecto de sus propios desequilibrios y "contradicciones" no llevan a que el mercado como tal desaparezca ni deje de funcionar, aunque ciertamente podrán afectar muy seriamente los niveles riqueza y pobreza y condiciones de vida de las personas, las organizaciones y empresas, los pueblos, las naciones y los estados.

Quinta precisión. El mercado en su funcionamiento interno puede marginar e incluso expulsar a determinados sujetos que participan en él. De hecho, en el mercado las más grandes e importantes empresas pueden caer en bancarrota, los países más ricos pueden entrar en decadencia, otros pueden entrar en situaciones de gran pobreza y miseria, y muchísimas personas pueden perder todos sus bienes y recursos. Pero lo más seguro es 
que el mercado siga funcionando, con nuevos, con distintos, e incluso con menos integrantes; pero se ve menos afectado de lo que se cree, por lo que ocurra a tales o cuales individuos, a tales o cuales grandes empresas, a tales o cuales países.

Sexta precisión. En el mercado participan de hecho todos los sujetos, individuales y colectivos, todas las organizaciones e instituciones, todos los Estados y las comunidades, todos los países y las regiones. La participación de cada uno de estos sujetos, sin embargo, puede ser y de hecho es muy diferenciada, en cuanto unos participan más y otros menos, unos lo hacen de un modo y otros de otro, cada uno ofreciendo determinados factores, productos y servicios y demandando determinados productos, servicios y factores. En el mercado, cada sujeto individual o colectivo se encuentra más o menos inserto, ocupando un lugar más o menos central o marginal. Toda "otra economía" deberá participar en el mercado; todos los sujetos, las empresas y las organizaciones de "otra economía", están condicionadas y necesitan hacerse un espacio de acción e intercambios en el mercado.

Séptima precisión. Alguien (un sujeto individual o colectivo de cualquier nivel que sea, incluido un país, o un grupo de países de una región del mundo) podría "salirse" del mercado y seguir subsistiendo, pero ello implica dos condiciones básicas. Una, que se haga totalmente autosuficiente en el sentido de ser capaz de proveerse de todos los bienes y servicios que necesita; y dos, que limite sus necesidades exclusivamente a aquellas respecto de las cuales puede proveerse autónomamente de lo indispensable para satisfacerlas. Condiciones éstas que, si bien se las examina, implican sacrificios extremos para quienes intenten cumplirlas. "Otra economía" que quiera hacerse independiente de las dinámicas del mercado, deberá asumir los costos que ello implica, y entre sus participantes deberá construir su propio mercado, acentuando las interacciones e intercambios entre quienes la integran. En tales intercambios entre sus integrantes, como también en los intercambios que estos establezcan con los del mercado general, podrá manifestarse la racionalidad diferente que las caracteriza, en cuanto actúen y se relacionen manteniendo sus principios, sus valores, su ética y sus modos propios de comportarse. Esto vale también para países completos que pretendan autonomizarse del mercado y de su crisis, e incluso para grupos de países de una entera región.

Hechas estas precisiones iniciales que tal vez permitan corregir algunas confusiones teóricas bastante habituales entre quienes buscan construir "otra economía", sigue abierta la interrogante clave respecto al sentido y la medida en que el mercado se altere en su funcionamiento, se trabe en sus dinámicas habituales, entre en crisis profunda, y que en tales contextos pueda cambiar y hacer posible que se abran espacios a la expansión de esa "otra economía". Comprender estas posibilidades nos exige detenernos sobre algunos conceptos económicos fundamentales y aplicarlos a la situación presente. 


\section{Profundizando en las causas de la crisis financiera global}

La actual crisis financiera está siendo entendida -en lo esencial- como efecto de una exagerada expansión del endeudamiento (especialmente de los mutuos hipotecarios, pero no sólo de estos), que ha dado lugar a un rápido incremento de la insolvencia y los incumplimientos de los deudores. Se acumulan de este modo en los bancos y entidades crediticias, títulos de deuda que carecen de valor, o que lo pierden en proporciones significativas. Se genera en consecuencia una pérdida de activos (o de valor) de los bancos y acreedores en general, que provoca la desconfianza de los inversionistas y tenedores de títulos, bonos y acciones, que se apresuran en deshacerse de estos papeles amenazados, y buscan refugio en activos que les proporcionen mayor seguridad. Con todo ello disminuye la capacidad de dar y de recibir créditos, lo cual se traduce en contracción económica y recesión.

Así entendida la crisis, se trata de un fenómeno "normal" y recurrente, que sucede periódicamente en los mercados. Lo que pudiera diferenciar la crisis presente de otras anteriores, sería solamente su profundidad y su extensión. En tal sentido, los números involucrados llevan a pensar que estaríamos ante una crisis cuya intensidad no se había visto desde la gran crisis de los años 1929-30.

El análisis de la actual situación de los mercados efectuado en base a los conceptos de la Teoría Económica Comprensiva, reconoce que lo expuesto (en los términos de las concepciones económicas convencionales) es correcto; pero va más allá y nos abre a otra dimensión de esta crisis, que la pone en una perspectiva histórica y económica que nos permite verla no solamente como más profunda y extendida sino como cualitativamente distinta. Más aún, nos pone en la perspectiva de comprender que las respuestas "normales" o habituales, aplicadas a esta crisis, no tendrán los efectos esperados, es decir, no conducirán en esta ocasión a una real superación y/o salida de la crisis.

La salida "normal" de una crisis financiera "normal" consiste en combinar en una adecuada (u óptima) proporción, tres elementos: a) la pérdida de valor de los activos de los acreedores; b) la pérdida que deben asumir los deudores; c) la pérdida que necesariamente ha de afectar al conjunto de los otros agentes económicos (consumidores, empresarios, trabajadores, etc.) vía inflación y/o vía contracción económica. De este modo se obtiene que la pérdida, el daño y el dolor que provoca la crisis se reparta (y diluya) entre los diferentes sectores involucrados. Estos procesos son cuidadosamente monitoreados por los Gobiernos (políticas fiscal, tributaria, regulatoria, subsidiaria y de incentivos, rescate de bancos, etc.) y por las autoridades monetarias o bancos centrales (tasas de interés, emisión monetaria, tipo de cambio, etc.).

Todo ello está de hecho ocurriendo. Pero desde el punto de observación que nos proporciona la Teoría Económica Comprensiva, podemos ver algo más, por debajo y más 
allá de todo lo indicado. (Como no podemos explicar aquí lo qué es y cómo procede la Teoría Económica Comprensiva, debemos limitarnos a exponer algunas conclusiones de un análisis que no podemos aquí explicitar. Baste por ahora decir que esta Teoría comprende los fenómenos y procesos económicos desde la intersubjetividad de las acciones, decisiones e intenciones de los sujetos privados y públicos que los producen, enmarcados en un determinado contexto institucional, jurídico y político).

Desde esta óptica apreciamos básicamente dos fenómenos de incalculables consecuencias:

El primer fenómeno es un cambio que se está cumpliendo en la naturaleza o "esencia "del dinero. Y como el dinero es -en el actual sistema económico- el elemento articulador de los mercados y de la economía en su conjunto, la presente crisis está significando una desarticulación estructural muy profunda de los determinantes del mercado, de modo que no podrá resolverse la crisis sino mediante una reforma institucional, jurídica y política. Entendamos: el mercado continuará funcionando, pero en crisis, que se prolongará hasta que se cumplan dichas reformas.

El segundo fenómeno, estrechamente conectado al anterior, es una mutación al nivel de las relaciones entre los agentes económicos privados y los agentes económicos públicos, tal que los equilibrios que han permanecido sin cambios sustanciales durante las últimas seis décadas ya no se sostienen, planteando la necesidad de redefinir las relaciones entre economía y política.

\section{El valor del dinero y la crisis financiera global}

El dinero (tan vilipendiado por algunos, tan amado por todos), es uno de los más importantes inventos y creaciones de la humanidad. En efecto, el dinero ha sido durante milenios y seguirá siéndolo hasta que inventemos una alternativa mejor, la solución a los más grandes problemas de la vida social.

Como ningún individuo, ni familia, ni grupo humano es autosuficiente, todos necesitamos intercambiar los bienes y servicios que necesitamos y que producimos. Los seres humanos nos necesitamos unos a otros, y trabajamos unos para otros. Esto da lugar al intercambio, al mercado, que cuando no existía el dinero se realizaba como trueque directo de unos bienes y servicios por otros bienes y servicios. Pero el trueque tiene dos problemas: es difícil de realizar (porque exige cada vez la coordinación empírica de las decisiones de cada oferente con las de cada demandante), y suele ser muy injusto (porque no hay un criterio ni mecanismo de medición del valor de los bienes y servicios que se intercambian).

El dinero resuelve estos dos problemas, al cumplir las siguientes funciones: 1. Servir 
como unidad de medida del valor de los factores, bienes y servicios económicos; 2. Servir de medio de cambio universal, coordinando las decisiones de todos los participantes en el mercado a través del sistema de precios.

Hay otros dos tremendos problemas económicos que el dinero resuelve. Los individuos y las sociedades necesitamos asegurar el futuro, lo que supone reservar y acumular la riqueza. Acumular los bienes físicos que constituyan riqueza (trigo, ladrillos, etc.) no siempre se puede y suele ser muy ineficiente, pues las cosas se dañan, pierden valor, se las roban. El dinero viene, entonces, a cumplir la función 3. Servir como medio de acumulación de riqueza, o servir para "reserva de valor".

Otro problema y necesidad que no encuentra solución sin el dinero, y que éste resuelve cumpliendo su función 4, es la de coordinar en el tiempo (coordinación intertemporal) las decisiones de los distintos agentes económicos, de manera tal que los recursos productivos y los bienes producidos estén disponibles para cada sujeto en el momento en que los necesita, sin permanecer inactivos o desocupados durante largos períodos de tiempo, o sin que haya que esperar acopiar todos los recursos antes de iniciar una actividad. Esto se conecta con la función 5. El dinero permite que lo que unos ahorran hoy (para gastar mañana) esté disponible hoy (en la forma de crédito o préstamo) para quien lo necesita ahora pero que sólo podrá pagarlo después.

Pues bien: ¿Qué pasa si el dinero deja de ser confiable como "unidad de medida" del valor? Imaginemos: ¿qué pasaría en la construcción de un edificio, de una catedral, de un castillo, si el metro que usamos para medir, un día mide 80 centímetros, el día siguiente mide $110 \mathrm{~cm}$., luego sólo 90, y nadie sabe realmente ni puede confiar en el metro que utiliza cada día?

En la historia ha ocurrido varias veces -y cada vez ha sido ocasión de una "gran crisis" económica- que el dinero ha dejado de ser confiable como unidad de medida del valor. Pues, cuando ello ocurre, deja el dinero de servir para acumular riqueza y reservar valor; ya no sirve tampoco para la coordinación intertemporal de las decisiones (pues ahorrantes y endeudados no pueden saber lo que vale lo que tienen hoy y lo que podrán tener mañana). Y se entorpece seriamente incluso la función del dinero como medio de intercambio universal.

Sostenemos que es esto lo que está ocurriendo actualmente. Mi tesis es que la actual crisis financiera es una "grande crisis" económica, cuya causa fundamental reside en la distorsión y el cambio que ha ocurrido a nivel de la "esencia" y las funciones del dinero. Y que, si es así, la crisis no se superará hasta que el dinero recupere su capacidad de cumplir correctamente sus funciones esenciales. En tal sentido, los "rescates" financieros que están implementando actualmente los gobiernos de muchos países no hacen sino agravar la crisis y postergar su superación, toda vez que contribuyen -y de manera muy importante-a 
acentuar la distorsión del dinero y dificultar que cumpla sus funciones esenciales.

Para que el dinero cumpla sus cinco preciosas funciones, es necesario que satisfaga dos condiciones esenciales, estrechamente asociadas. La primera es que el dinero tenga valor, que represente valor realizable en el mercado. Para ello debe tener -como se dice- un "respaldo" adecuado y consistente. La segunda condición es que sea "confiable" para todos los agentes económicos.

Que el dinero tenga valor, que esté respaldado por riqueza real, es una necesidad obvia, toda vez que es el activo económico que se intercambia por bienes, servicios y factores reales. Nadie cambiaría algo que vale por algo que no vale.

Que el dinero sea confiable es una consecuencia del respaldo que lo sostiene, y además, de que esté vigente jurídica e institucionalmente el "contrato social" o la convención intersubjetiva según la cual se fija la "unidad de medida" del dinero que se emplea en las transacciones, que garantiza la genuinidad del dinero circulante, y que castiga los incumplimientos de los contratos comerciales. En la época moderna esta garantía de confiabilidad está dada por el Estado y su ente financiero central, que emite dinero de curso legal.

Es de la esencia del dinero que "tenga valor", que esté respaldado.

Antiguamente el dinero que se empleada en las transacciones tenía valor en sí mismo: se trataba de porciones de oro, plata y metales preciosos.

Posteriormente se colocó el oro en la bóveda de los bancos, que emitían billetes de papel "convertibles" en oro o plata.

Después se descubrió que no era necesario que el dinero tuviese respaldo en oro, pues podía respaldarse directamente en los bienes y servicios por los cuales se intercambiaba en el mercado. El que emitía el dinero garantizaba que tenía activos económicos suficientes para respaldar la emisión monetaria y responder por el valor del dinero.

Más adelante se pensó que no necesariamente fuera el emisor quien debía disponer de valores equivalentes al dinero emitido, pues bastaba que el conjunto del dinero estuviera respaldado por el conjunto de bienes y activos económicos existentes en un mercado determinado.

Pero, para que ello generara la indispensable confianza, fue necesario que el Estado tuviera el monopolio de la emisión del dinero, garantizando que no emitía dinero nuevo sino en proporción al crecimiento de la producción. (Si no cumplía con parsimonia con este requisito, esto es, si realizaba emisiones "inorgánicas", el dinero se desvalorizaba en el 
mercado produciendo inflación que reducía el valor de la unidad monetaria).

En fin, recientemente, se inventó que podía emitirse dinero sin respaldo actual en activos económicos existentes en el mercado, siendo suficiente que el respaldo lo otorgara el conjunto de los compromisos de pago futuro asumidos por los sujetos económicos que recibían el dinero en forma de préstamo o crédito. El respaldo consiste, actualmente, solo en creer que los deudores pagarán el dinero que ha sido emitido expresamente como crédito.

Es así que, hoy, el dinero se emite como deuda, y esto lo realizan los bancos privados, las empresas, e incluso los supermercados y todos los negocios que emiten dinero al aceptar pagos diferidos en el tiempo.

Este dinero, pues, está respaldado exclusivamente por deudas: así, el dinero "es" deuda. El respaldo del dinero no está en activos económicos actuales, sino en producción y riqueza futura. El banco emisor de dinero -el banco privado o la empresa comercial que crea dinero en el momento que concede crédito a sus clientes- puede exigir que el cliente le garantice el pago, por ejemplo, mediante la hipoteca de un bien inmobiliario cuyo valor sea equivalente al crédito. Pero puede también concederle el crédito sin obtener del deudor una garantía suficiente.

Es en este último sentido que se dice, para explicar la actual crisis financiera, que ella se origina en la burbuja de los precios de los bienes inmobiliarios hipotecados como garantía de los créditos, que no han mantenido su valor.

Dejemos a parte, por ahora, el hecho que la Reserva Federal de Estados Unidos ha sido autorizada para emitir mucho dinero (700.000.000.000 de dólares) respaldados por papeles, bonos y otros documentos de pago que se sabe que no tienen valor, que son deuda morosa, incobrable, casi sin valor real. Este es, en los hechos, el último paso en el proceso de pérdida de valor del dinero.

Lo que se intenta con este "rescate" es que "los mercados" (o sea los agentes económicos) recuperen la confianza en los bancos y se evite el temido pánico con que se recuerda la grande crisis de 1929.

Sí, todos hoy hablan que el sistema financiero se basa en la confianza, que el dinero está sustentado en la confianza, en la credibilidad.

Pero esto es solamente una parte de la verdadera esencia del dinero, como hemos visto. Nuestro análisis nos permite comprender que la cosa es muy diferente, y que el problema es mucho más profundo, y que afecta al conjunto del dinero emitido, y no solamente a las deudas morosas.

El cambio sustancial que ocurre a nivel de la naturaleza del dinero, cuando se lo emite en base a deuda y se lo respalda en función de sus pagos futuros, deriva del hecho 
que toda deuda implica un compromiso de pago por una cantidad mayor de dinero que la recibida en préstamo. En efecto, debe pagarse el interés. Y como casi todo el dinero emitido y circulante ha sido emitido contra deuda, ocurre inevitablemente que el monto total de los compromisos de pago es mayor al monto del dinero real circulante. Por definición, los billetes puestos en circulación no alcanzan para amortizar los créditos y además pagar el interés convenido. Así, gran parte de la deuda no puede ser nunca pagada.

Esto puede sostenerse en el tiempo solamente mediante la inflación (que diluye el valor del dinero en el tiempo) y en base al incremento permanente de la producción, que permite respaldar una parte de los intereses por pagar.

Pero la inflación hace que el dinero pierda credibilidad y confiabilidad. Y el crecimiento permanente sería posible solamente si el incremento de las deudas (dinero creado en el mercado) fuera proporcional al incremento de la producción.

Esto último es lo que ha fallado, en proporciones gigantescas, en las últimas décadas. A través de los derivados de crédito, contratos a futuro, etc., el monto total de las deudas se ha incrementado exponencialmente. Sólo un dato para ilustrarlo: el total de las deudas (dinero) vigentes en la economía de los Estados Unidos (incluidas las deudas públicas y privadas, los bonos, hipotecas, déficit público, etc.) es actualmente 300 veces el Producto Interno Bruto de USA. Trescientas veces es demasiado para que se pueda seguir confiando en que el dinero "vale". El respaldo del dinero creado como crédito es una porción ínfima del valor atribuido al dinero.

De ahí la actual crisis, que sin duda ninguna, será grande. El crédito está disminuyendo aceleradamente, porque no hay confianza en que lo que se preste será recuperado. Por eso, el dinero "contante y sonante", los billetes de curso legal, adquieren un enorme valor. Esta grande crisis será muy profunda, y durará hasta que no se cree un nuevo sistema monetario: un dinero de nuevo tipo, que valga, que esté respaldado, y que suscite la confianza. Ello requiere, a su vez, un nuevo orden político, institucional y jurídico.

\section{¿Puede una política keynesiana servir para superar la gran crisis actual?}

Se está dando actualmente un renacer del keynesianismo. Muchos recuerdan que el New Deal tanto en América como en Europa produjo decenios de bienestar: ocupación y elevación del nivel de vida de la población, junto con la superación de la gran crisis de los años treinta. Tal es una creencia actualmente muy difundida, que explica también por qué casi todos tienden hoy a pensar que para salir de esta crisis se requieren políticas 
keynesianas: más Estado, más crédito, más emisión monetaria, más regulaciones.

Es sabido que la historia la interpretan los vencedores; pero no por ello la interpretación resulta científicamente rigurosa y verdadera. Pero a las creencias sobre el keynesianismo difundidas y proclamadas durante las seis últimas décadas del siglo pasado hay que hacerles algunas correcciones importantes:

1. El New Deal aplicado por Roosevelt entre 1933 y 1937 (consistente básicamente en un gran intervencionismo del Estado en el mercado, y un consistente fomento del consumo mediante la emisión monetaria), lejos de salvar al mundo de la gran depresión como se cree, en realidad hizo que la crisis se prolongara durante una década completa, prácticamente en todo el mundo, hasta el comienzo de la guerra.

2. El impresionante auge económico que se observa después de la segunda guerra mundial ¿es explicable por el keynesianismo? La respuesta que podemos dar desde la Teoría Económica Comprensiva -que comprende los procesos económicos en su contexto histórico, político y cultural- es negativa. El llamado keynesianismo fue causa de la notable distribución de la riqueza, que generó un mercado más equitativo y en cierto modo más democrático; pero no fue causa relevante del crecimiento económico ni de la generación de riqueza.

Hay un hecho de dimensiones gigantescas pero que permanece bastante oculto por razones ideológicas: la guerra y la economía de guerra están al origen del impresionante auge económico de la postguerra. En efecto, la guerra puso las bases tecnológicas, sociales, institucionales, políticas y demográficas que explican el gran impulso que experimentó la economía durante los treinta años siguientes.

Destacan, en particular, los siguientes 7 impactos de la guerra, cada uno de ellos condicionantes del auge económico posterior:

a) La guerra generó innovaciones tecnológicas impresionantes (en los rubros energético, de las comunicaciones, el transporte marítimo y terrestre, la aviación, la ingeniería de obras civiles, la ingeniería industrial, la automatización, la electrónica, la industria química, la medicina, la producción de alimentos, etc.) que, después, aplicadas en la producción y la economía civil, impulsaron la innovación productiva y una increíble expansión de la productividad.

b) Produjo una gran acumulación de capital, concentrado en gran medida en manos del Estado, que permitió que éste fuese un actor decisivo en la industrialización, la urbanización, la tecnología, la educación, la salud, etc. durante los siguientes 30 años de la postguerra.

c) Dio lugar a una clase trabajadora disciplinada y eficiente, que era necesaria para el desarrollo industrial.

d) Permitió que se alcanzara una sorprendente disciplina social, que facilitó el 
establecimiento de instituciones fundamentales para el desarrollo.

e) Dio legitimidad al Estado para implementar políticas fiscales (elevados impuestos) y distributivas (estado de bienestar) que le permitieron mantener al Estado como agente económico principal durante décadas.

f) Generó condiciones para la movilización de recursos naturales, sociales y demográficos en vistas de la realización de proyectos nacionales de envergadura.

g) Estableció y consolidó una división internacional del mercado (con términos de intercambio extremadamente desiguales), que generó una sistemática transferencia de recursos hacia Estados Unidos y Europa, desde América Latina, Asia, África y todo el resto del mundo que permanecieron en el subdesarrollo (no obstante que también allí se aplicaron las políticas keynesianas). A lo anterior hay que agregar otro condicionante, que no fue efecto de la guerra pero que incidió notablemente en el crecimiento económico durante la segunda mitad del siglo pasado: la impresionante expansión de la disponibilidad de energía de bajo costo, especialmente proveniente de los hidrocarburos.

3. De este modo -como efecto inmediato de la guerra y como actor capaz de aprovechar las oportunidades creadas durante aquella- el Estado pudo ser y de hecho fue, en los países desarrollados, un gran impulsor del auge económico durante la posguerra.

El keynesianismo fue la concepción económica que acompañó durante treinta años dicho auge económico, y su principal mérito fue hacer que la riqueza se distribuyera de manera más equitativa en la sociedad, a través de políticas sociales y de bienestar. Pero políticas neo-keynesianas irresponsables en el plano monetario, un exceso de regulaciones estatales, impuestos demasiado elevados, y una gran presión social y política para que el Estado se hiciera cargo de cuanta necesidad colectiva y/o demanda corporativa alcanzara cierta notoriedad, condujeron a que en sólo 30 a 35 años, el impulso económico se debilitara, la moneda se envileciera, y la crisis volviera a producirse a fines de la década de los setenta y comienzos de los ochenta.

¿Qué queda hoy de los 7 condicionantes del auge de la posguerra? En verdad, el Estado parece haberlos dilapidado.

4. Las políticas keynesianas no pueden ya ser útiles para enfrentar la actual crisis. Ello, en el corto plazo, porque no podrían tener siquiera los reducidos efectos positivos que tuvo el New Deal en los años treinta frente a la crisis. En efecto, si hubiera que reconocer que en las condiciones de entonces las medidas aplicadas por el New Deal eran razonables, ya no lo son actualmente. En efecto, las condiciones en que se aplicó el New Deal eran muy diferentes a las actuales. Había entonces un evidente subconsumo, hoy venimos de un notable consumismo. Escaseaba el dinero, por las elevadas tasas de interés; hoy abunda la emisión monetaria, con tasas de interés muy bajas durante períodos muy prolongados. Regía el patrón oro y la convertibilidad en oro que daban un excesivo respaldo al dinero; 
actualmente el dinero se crea "ex nulla", o su respaldo es solamente el "crédito". En ese tiempo era altamente premiado el ahorro; actualmente y desde hace mucho tiempo el ahorro es castigado por la inflación y las bajas tasas de interés.

En cuanto al mediano y largo plazo, no vemos al Estado como actor que pueda encabezar la recuperación y un nuevo auge económico, porque:

a) No parece capaz de generar dinámicas de innovación tecnológica consistentes.

b) Lejos de disponer de abundante capital acumulado, la mayoría de los Estados experimenta déficit elevados.

c) No parece capaz de disciplinar y motivar a la clase trabajadora en un gran esfuerzo de trabajo con fines de desarrollo nacional.

d) Las instituciones públicas se encuentran debilitadas, incluso a menudo éticamente corrompidas, y cuentan con escasa capacidad de entusiasmar en torno a proyectos nacionales.

e) La sobreexplotación de muchos recursos naturales pone límites (incluso culturales) al crecimiento por su incidencia en el medio ambiente y la ecología.

f) La emergencia de grandes sociedades que estaban sumidas en el subdesarrollo pone límites a la transferencia fácil de recursos hacia los países avanzados.

g) La disponibilidad de energías de bajo costo se encuentra seriamente amenazada.

Ninguna de estas condiciones que en la posguerra hicieron posible que el Estado se alzara como el gran agente del desarrollo pueden, hoy, ser activadas mediante un nuevo conflicto bélico. Al contrario, por razones que no es del caso exponer en esta ocasión, de la guerra no puede hoy esperarse sino la aceleración de la descomposición y la decadencia económica, social y cultural.

Si es así, ¿cómo podremos salir de esta crisis? Si no es el keynesianismo, ¿qué otra alternativa de respuesta puede formularse?

\section{¿Qué otras opciones y escenarios son actualmente posibles?}

En una primera instancia de análisis y búsqueda de alternativas, se presenta una cuestión fundamental, de la cual dependen muchas otras, por lo que conviene referirse a ella en primer lugar. Es la cuestión de las "dimensiones" geo-económico-políticas del posible nuevo ordenamiento mundial.

Una primera opción la podemos llamar "mundialización económico-política", que supone avanzar en la dirección de una globalización acentuada, que pudiera manifestarse en una serie de procesos entre los que destacarían: 
a) La creación de una moneda única mundial (sustitutiva del dólar, el euro, el yen y todas las monedas nacionales).

b) El establecimiento de una institucionalidad económica que fije regulaciones financieras, comerciales, fiscales, energéticas, ambientales, laborales, jurídicas e incluso militares, que deban regir y aplicarse en todas las naciones del mundo (con la sola exclusión de aquellos países que soberanamente quieran sustraerse del sistema y que quedarían política y económicamente aislados).

c) Se implica en este escenario una dramática reducción del poder de los Estados nacionales, que entre otras muchas atribuciones que posee actualmente perdería la capacidad de poner restricciones al libre comercio.

Una segunda opción la podemos llamar "regionalización económico-política", que implicaría el surgimiento de tres grandes regiones económicas que competirían entre ellas por el control de los mercados (y de los principales recursos) mundiales, y por el dominio y/o la hegemonía política internacional.

En este escenario podemos visualizar la formación y consiguiente confrontación entre grandes regiones geográfica, económica y políticamente configuradas, que serían América del Norte, la Unión Europea y un Bloque Asiático.

Cada una de estas potencias tendría su propia moneda y sistema financiero, fijaría sus propias regulaciones, inclusivas de un fuerte proteccionismo de sus mercados y fronteras económicas, y compitiendo por los recursos y los mercados de las zonas que permanecerían probablemente sin integrarse a dichas regiones, tales como América Latina, Rusia, los países petroleros, etc.

Una tercera opción sería el prevalecer de los estatismos nacionalistas, con la mantención de las monedas nacionales, el incremento de las políticas proteccionistas, el aumento de las restricciones al libre comercio, el Estado nacional asumiendo crecientes funciones, y probablemente dándose lugar al recrudecimiento de los conflictos y guerras entre países.

Formular estos tres escenarios posibles es en realidad un ejercicio intelectual menor. También es fácil imaginar que las tres opciones tendrán sus promotores e impulsores, de modo que durante un cierto período de tiempo veremos y podremos seguir el debate y la confrontación entre estas tres opciones. Lo verdaderamente complejo y que plantea desafíos intelectuales mayores, lo podemos diferenciar en dos aspectos.

El primero es prever el curso de los acontecimientos, identificar a los actores (incluidas las naciones) que se pondrán a favor de cada opción, visualizar la relación de fuerzas que se manifestará entre ellos, y adelantar el resultado histórico-político de la confrontación (que será, obviamente, teórica y práctica). 
El segundo, por cierto distinto del anterior aunque el pensamiento ideológico tiende a menudo a confundirlos, es identificar cuál de las opciones señaladas es la mejor, o la más conveniente y adecuada en términos de superar la crisis actual y de alcanzarse un mejor futuro para la humanidad.

\section{¿Por cuál de estas opciones, y con qué otros componentes, pudiera vislumbrarse una salida de esta gran crisis?}

Antes de abordar esta pregunta volvamos la mirada sobre la magnitud e intensidad de esta gran crisis. Pues se habla y escribe con demasiada facilidad sobre "la salida de la crisis". Se anuncia que ella durará dos o tres semestres, o un año, incluso algunos dicen que hasta dos años completos. Este último es el escenario que la describe como una crisis en forma de U, imagen con la cual se indica que a la caída acelerada seguirá una relativamente prolongada situación depresiva, luego de la cual inevitablemente vendrá la subida, que se espera será tan acelerada como fuera la caída. Nadie, en efecto, duda que de esta crisis se sale, y que la economía recuperará el crecimiento, volviendo a la normalidad, e iniciándose un nuevo ciclo de expansión y crecimiento.

Se piensa y razona de este modo, porque se concibe que esta crisis es una más entre las crisis cíclicas que acostumbra experimentar el mercado.

Yo no lo creo. Cuando sostengo que esta crisis será prolongada, no pienso en dos o tres años, sino en tantos cuantos se requieran para que se cumplan las condiciones de salida de esta crisis, a los que me he referido en post anteriores y que podemos resumir así: Una nueva moneda internacional, un nuevo orden financiero, un nuevo ordenamiento institucional, jurídico y político de dimensiones globales, y una nueva cultura que implique una transformación profunda de los comportamientos económicos de las personas, grupos y sociedades. Así, la crisis podrá durar tres años, cinco años, diez años, veinte años, o más. Menos o más, dependiendo de lo que nos demoremos en crear estas nuevas condiciones.

Cuando afirmo que esta crisis será profunda, no pienso en uno, dos o hasta tres puntos (como creen los más pesimistas) de decrecimiento, sino en una caída generalizada de la producción y del consumo, tanto o más grande como la que ocurriera con la crisis del 1929-30, y cuya efectiva superación empezó solamente al término de la Segunda Guerra. Obviamente, en este juicio está contenido un cierto concepto de la crisis, que comprende las dimensiones económica, social, política y cultural.

Observemos algunos hechos.

Primer hecho. Hace apenas 4 meses (mediados de Julio 2008) el petróleo alcanzaba casi 150 dólares el barril, y los analistas anunciaban que llegaría rápidamente a 200 dólares, y algunos planteaban cifras mayores. ¿Se equivocaron los analistas? Obviamente, en cierto 
sentido, pero ello no tiene mayor importancia. El hecho es que el petróleo llegó a costar 150 dólares, y que "el mercado" prospectaba que el precio seguiría subiendo aceleradamente. Todo ello estuvo acompañado de otros dos hechos: a) Una sorpresiva difusión de la teoría del "peak oil" de Hubbert, según la cual se avecina una catástrofe como consecuencia de que no existen capacidades productivas ni reservas de petróleo capaces de mantener en el tiempo los niveles actuales de producción de esta fundamental fuente de energía. b) Los gobiernos de todo el mundo realizaron una campaña coordinada tendiente a reducir el consumo energético y a buscar fuentes alternativas; una campaña que tuvo escasos resultados.

Segundo hecho. En el momento en que el precio del petróleo llegó a su máximo histórico, se inició una brutal contracción del dinero disponible en la economía, que generó una "sequía" del crédito, no solamente al consumo y a las hipotecas inmobiliarias, sino también a las más grandes empresas. Los índices de las Bolsas de valores caen entre un 40 y un $70 \%$ en todos los países del mundo. Al mismo tiempo se derrumban entre un 25 y un $60 \%$ los precios de las viviendas y de las principales materias primas.

Tercer hecho. Los Bancos Centrales y los gobiernos en todas partes salen simultáneamente "al rescate" selectivo de los principales bancos y empresas que se tornan insolventes, evitando así que entren definitivamente en bancarrota.

¿Hay alguna lógica detrás de todo esto?

He leído muchas explicaciones que dan los analistas, respecto a cada uno de estos hechos considerados aisladamente. Una explicación distinta para cada hecho. Todos, hechos que se explican por "el mercado", afectado por desequilibrios, que motivan acciones especulativas, pánicos, comportamientos esquizoides, en fin, "volatilidad" extrema. Detrás de ello, por cierto, burbujas que se inflan y desinflan. ¿Es eso todo?

Con nuestra Teoría Económica Comprensiva tratamos de comprender los procesos, aplicando una estructura conceptual compleja. Resumimos las hipótesis a las que hemos llegado.

1. El mercado determinado, actualmente no está funcionando como un mecanismo automático que responde a decisiones independientes de sujetos en competencia. El mercado determinado tiene un nivel de extrema concentración, y responde en gran medida a las decisiones de pocos gigantescos y muy poderosos grandes grupos económicos, y se encuentra comandado y articulado por pocos y muy determinados grandes poderes públicos nacionales y supranacionales. (Para entendernos, grandes fondos de inversión, la Reserva Federal, el Tesoro de los EE.UU, el BCE, el G8, el FMI y poco más).

2. Existe, efectivamente, un gravísimo problema de escasez de petróleo, cuya 
producción no alcanza a sostener ya el crecimiento de la economía a nivel global, y cuyas disponibilidades (reservas no explotadas) no permitirán mantener durante las próximas décadas ni siquiera los niveles de producción actuales. (Ver y leer cuidadosamente -incluso entre líneas- el Informe reciente de la World Energy Outlook en www.worldenergyoutlook.org ). Desde este punto de vista, y hasta que no se resuelva el problema energético con nuevos descubrimientos, nuevas tecnologías, nuevas soluciones, el mundo se verá enfrentado a una inevitable contracción económica.

3. Si el mercado estuviese operando en libre, espontánea y automática competencia, el escenario más probable sería catastrófico. Pero el mercado determinado se encuentra controlado y comandado, como sostiene nuestra hipótesis 1. Y quienes comandan el mercado, han decidido asumir el problema de la doble crisis (energética y financiera) en su real magnitud, y evitar la catástrofe, imponiendo una profunda y prolongada depresión económica.

4. Lo que han hecho para evitar la catástrofe, puede sintetizarse en los siguientes movimientos:

Primero, con el petróleo a 150 dólares estuvimos (nos llevaron) al borde del abismo de una posible crisis energética. Ello nos hace comprender a todos, que el crecimiento económico sostenido no es ya posible.

Segundo, con la contracción monetaria y la consiguiente inevitable depresión, se espera evitar el colapso energético (con una fuerte contracción de la demanda de petróleo), pero ello nos pone al borde de otro abismo, el del colapso financiero global. Así comprendemos que será necesario adaptarse a una economía no sólo sin crecimiento sino en depresión, por un largo tiempo.

Tercero, con los "rescates", las nuevas regulaciones, el control de los grandes bancos y de las grandes empresas automotoras, aerolíneas y otras, los grandes poderes se aprontan a tomar el control de la situación y así manejar una prolongadísima y profunda gran crisis. Comprendemos que bajo tales comandos una crisis profunda y prolongada no sería la peor alternativa. Este tercer momento no será sin conflicto entre muchos grandes intereses involucrados, pero terminará por establecerse (con el predominio de alguno de los tres escenarios que expusimos en el punto anterior).

En los próximos años y tal vez durante décadas, viviremos en depresión económica, oscilando entre dos abismos mucho peores: el abismo de la crisis energética y el abismo de la interrupción de la cadena de pagos. El avance por tan estrecho sendero será dramático, pues para evitar caer en el abismo energético será necesario reducir el crecimiento económico (la producción y el consumo). Pero al reducir el crecimiento se hace insostenible el funcionamiento del sistema financiero, que solamente puede operar con cierta normalidad si hay crecimiento de la producción y del consumo. Así caminaremos por 
el estrecho sendero de una crisis prolongada y profunda, entre dos abismos catastróficos: intentando evitar el primero nos asomaremos al segundo, y evitando caer en el segundo nos asomaremos al primero. Nos mantendremos en la grande crisis sólo si logramos evitar caer en cualquiera de los abismos.

\section{¿La salida?}

En el supuesto de que evitamos el abismo y la catástrofe, podremos decir que se ha iniciado la superación de la gran crisis cuando avancemos simultáneamente en la construcción de las siguientes cuatro condiciones:

1. Disponer de un nuevo sistema monetario y financiero, que no requiera elevado crecimiento de la producción y del consumo para sostenerse. Ello supone que el dinero deja de crearse como crédito, y que recupere credibilidad y sus cinco importantes funciones.

2. Disponer de una nueva matriz energética, ambientalmente sustentable.

3. Una gran reforma intelectual y moral, que sustente un nuevo modo de vida, una nueva economía, una nueva cultura, orientadas hacia el levantamiento de una nueva civilización, más justa y solidaria.

4. La creación de un nuevo orden institucional, jurídico y político, que de estabilidad y garantice la permanencia de las tres condiciones anteriores. 


\section{Bibliografía}

Academia Nacional de Ciencias Económicas de Venezuela (2006), Revista Nueva Economía, Año XV, $N^{\circ} 26$, Diciembre 2006, Caracas.

Arango Jaramillo, Mario (1997), La Economia Solidaria. Una Alternativa económica y Social, Ediciones CORSEVA, Medellín.

Catan, Antonio David (org.) (2004), La Otra Economía, Fundación OSDE, Universidad Nacional General Sarmiento, Editorial Altamira, Buenos Aires.

Internacional Energy Agence (2008), World Energy Outlook 2008 Edition, OECD-IEA.

Razeto Migliaro, Luis (1994), Fundamentos de una Teoría Económica Comprensiva. Ediciones, PET, Santiago.

Idem (2001), Desarrollo, Transformación y Perfeccionamiento de la economía en el Tiempo, Ediciones Universidad Bolivariana, Santiago. 